\title{
A CROSS-CULTURAL STUDY OF NEUROPHILOSOPHY
}

\author{
Kai-Yuan Cheng \\ National Yang-Ming University, Taiwan
}

\begin{abstract}
This paper will discuss the prospects of neurophilosophy based on the works of Georg Northoff (2014a, b), a leading brain scientist and philosopher who has been conducting pioneering experiments on the neural-basis of self and consciousness. Engaged in vigorously philosophical thinking about the future of neurophilosophy, he claims that the empirical and the conceptual domains can and should be combined in a manner so as to significantly advance our understanding of the human mind. His conception of the brain as an organ that is intrinsically interconnected with a body and its environment sets him apart from some other influential neurophilosophers. Thus, the main purpose of this paper is to suggest that Northoff's neurophilosophical project be situated and considered in a broader context, that is, in the context of Chinese Philosophy, such that insights and potentials on both sides may be better appreciated and more fully developed in future inquiries. To motivate my undertaking of a somewhat unusual and unexpected task like this, which is to connect two very different traditions-Eastern and Western-in a contemporary neural-inquiry of the human mind, some preparatory work is needed.
\end{abstract}

Keywords: Neurophilosophy, Brain Science,

Consciousness, Self, Mind 


\section{Introduction}

Neurophilosophy is an interdisciplinary study of neuroscience and philosophy. It aspires to integrate insights and methodologies from each respective field in a way that can be conducive to shedding fresh lights on the nature of human mind, especially self and consciousness. The emergence of such a trend is natural and easy to understand, but it remains perplexing how these two disciplines could be related in productive ways.

On the one hand, both disciplines have a common interest, be it direct or indirect, the mind. Philosophers have long puzzled over and purposed models of our consciousness and our perceived sense of self, while neuroscientists have been uncovering the physical mechanics that operates our brain. It is not difficult then to see how the careful conjoining of the physical evidence and the theoretical frame work will lead to better understanding of the mind for each discipline. However, it is not obvious to see how any illuminating integration of these two research areas may be plausible or even possible. The brain is made of grey matter, and exists in the physical realm; it can be thoroughly investigated objectively from a third-person perspective. In contrast, the mind, consciousness and self can only be investigated subjectively from first-person perspective that appears to define what they are. How, then, could philosophy, aimed at offering conceptual analyses of the subjective realm, contribute to brain neuroscience that focuses on empirical inquiries of the objective items in any significant ways, and vice versa? Perhaps the best we can hope for from such an integral inquiry is a study of a mere systematic correlation between the physical and mental realms.

In this paper, my discussion of the prospects of neuro-philosophy will be focused on the works of Georg Northoff (2014a, b), a leading brain scientist and philosopher who has been conducting pioneering experiments on the neural-basis of self and consciousness and engaged in vigorously philosophical thinking about the future of neurophilosophy. His main claim is that the empirical and the conceptual (including the metaphysical, the epistemological and the ethical) domains can and should be combined in a fruitful way such as to significantly advance our understanding of the human mind. An innovating idea lies in his conception of the brain not as an isolated item which by itself is capable of producing a sense of self and consciousness, but as an organ that is intrinsically interconnected with a body and its environment. This view 
distinguishes Northoff from some other influential neurophilosophers such as Patricia and Paul Churchland $(2002,2007)$ who tend to reduce the main production of a sense of self and consciousness to the workings of a brain. In a non-reductive version of neurophilosophy proposed by Northoff, consciousness and a sense of self are not simply features of the brain, but are characteristics that have to be understood in terms of something greater than the brain, something that encompasses body and its external environment.

The main purpose of this paper is to suggest that Northoff's neurophilosophical project be situated and considered in a broader context, in the context of Chinese Philosophy, such that insights and potentials on both sides may be better appreciated and more fully developed in future inquiries. To motivate my undertaking of a somewhat unusual and unexpected task like this, which is to connect two very different traditions-Eastern and Western-in a contemporary neural-inquiry of the human mind, some preparatory work is needed.

I will first explicate the notion of law and that of shi (勢). This is a contrasting pair of notions deeply rooted in Western and Eastern civilizations brought to our attention by a French sinologist and philosopher Francois Jullien (1995, 2004). This would pave the way for uncovering an implicit but widespread presupposition in the Western civilizations, that a property of an object or subject is intrinsic to the object or subject. Even if a relational property between two objects is conceivable and employed in the Western traditions, objects typically come into the picture as primary and relations between them only secondary. The Eastern traditions do not hold on to this presupposition to an extent comparable to the Western world. It will be contended that this very fundamental assumption is likely to constitute a major obstacle for certain ground-breaking ideas to be proposed and appreciated, such as Higgs' boson theory in physics, as well as Northoff's nonreductive view of consciousness and self in neuroscience. Chinese Philosophy is, finally, brought into the picture to show that an intellectual tradition free of the intrinsic-property assumption has a tendency to conceive of the human mind as an integral part of a human body and its inhabited environment. Toward the end, the significance of conducting a cross-cultural study of neurophilosophy will be discussed.

\section{Law and Shi}


For us humans to navigate and survive well in this complex worldphysical, social, military, political, or otherwise, possession of a suitable conceptual repertoire is crucial. Suppose a person had no idea about the possible trajectory of the movement of an object in a variety of circumstances, such as a heavy stone's being placed on a slippery hill right above one's own house, the person would obviously put his property and even life under risk. If a general did not believe that troops with a better training and [higher] morale is more likely to defeat another troop of similar conditions but without the two mentioned qualities, the prospect of the general's winning a battle would be dim. Jullien (1995, 2004) has made an impressively clear and compelling case for the claim that the Chinese and the European possess very different conceptual frameworks when they face the same world and get around in it.

As Jullien maintains, the notion of law is fundamental in the Western thinking about the world, while that of shi is basic to how the Chinese conceives of the world. Take Newton's law of gravitation as a paradigmatic example. It states that any two bodies in the universe attract each other with a force that is directly proportional to the product of their masses and inversely proportional to the square of the distance between them. A law of this sort states a universal principle, meaning that for any object at any time, the stated relation between two objects holds. In other words, a law of gravity governs how a physical object moves in the universe. In contrast, the notion of shi is a sort of a composite concept, consisting of the concept of dispositive and that of disposition. The former concept refers to the deployment or arrangement of an object in a specific circumstance. The latter concept refers to some propensity or capacity latent in an object. Note that the propensity of an object is inseparable from how it is deployed in a specific circumstance. A stone has a greater tendency to move when it is placed on a hill than on a flat surface, with an even greater momentum to move when its shape is round compared to when the shape is square, etc. Jullien thus makes a fair comment that the Chinese appears to apply the concept of shi ambivalently between these two concepts, and suggests that the notion of configuration be used to denote a composite idea like shi.

According to this Chinese worldview, there may be some regularity of movements under specifically and repeatedly occurring deployments of objects, but it is manifested from and brought about by dispositions or propensities inherent in the deployment of those objects. No such thing as a regulating law exists independently of the deployments and of the dispositions inherent in them, contrary to how a 
Western worldview has it. Jullien has further made a point with deep insight that a law-based worldview in the Western traditions is rooted in a conception of the world with a God, and that a shi-based worldview in the Chinese traditions gives a picture of a God-less world. In the former case, an object cannot move by itself, but can only move through the aid of God. In Newton's idea, the law of gravity derives its autonomy of governing how an object moves from the existence of God. God is posited as the first cause of all things that move, a view that can be traced back to Aristotle's philosophy. In the latter case, in contrast, the ancient Chinese construes objects as being intricately interrelated in a holistic chi-based (often understood as energy) unity capable of moving itself without having an ultimate cause being identified.

In a recent paper (Cheng, 2014a), I have tried to criticize Jullien's comparative work by updating it with and situating it within a contemporary Western context of philosophy of science and metaphysics. I have argued that some philosophers of science such as Nancy Cartwright (1983, 1989, and 1999) have proposed a worldview where objects have capacities or natures from which laws may be derived. More specifically, laws have a status of statements trying to capture the regularities of behavior that are manifested by capacities of objects in highly specific and repeated circumstances. Cartwright calls these law statements as "nomological machines". Law statements can be said to be true, but only enjoy a secondary status. It is a capacity possessed by an object that is real and fundamental. Some metaphysicians like John Heil $(2004,2015)$ have also opted for a picture of world where dispositions are ontologically basic and their complex interconnected networks explain why and how objects behave the ways they do. Laws, in the eyes of Heil, are redundant items which have their roots in a God-based worldview typical in the Western traditions. Against this updated comparative background, Jullien appears to miss an obvious fact that ancient Chinese thoughts and modern Western ideas can be strikingly similar when it comes to understanding and explaining phenomena in the world.

\section{Dispositions: Intrinsic versus Extrinsic}

Despite the fact that both modern Western philosophers and ancient Chinese thinkers do without the notion of law and posit that of disposition or capacity to understand and navigate in the world, a critical 
difference lies in how a disposition or capacity is conceived of on both sides.

In the modern West, Cartwright and Heil both view a disposition or capacity as some intrinsic property inherently possessed by an object. As Heil explicitly states: "I want only to insist on a conception of dispositions according to which they are intrinsic properties of objects" (2005: 345). Cartwright also regards a capacity as a "nature" of an object, which is clearly an inherent property of an object. In ancient China, although it might not have been explicitly articulated whether a disposition or capacity is intrinsic or not, it is noticeable in many writings about practical matters such as warfare in which an extrinsic view is held. For example, when a Chinese general deploys a troop, considerations of whether soldiers are brave or not are not necessarily required. Rather, the kind of circumstances under which soldiers are deployed could be considered with a higher degree of priority. For instance, when deployed against a cliff while facing invading enemies, all soldiers, brave or not, would become brave. This clearly shows that a disposition of an object or subject is rarely considered or characterized in isolation from the circumstances of the object or subject. In contrast, a Westerner would have had a hard time not to conceive of a dispositional property such as bravery or fragility as an intrinsic property possessed by a person or a glass.

Cartwright and Heil are not alone in assuming that dispositions and capacities are intrinsic. Many philosophers simply claim that dispositions are intrinsic properties of objects without offering any arguments for the claim. For example, George Molnar states: "Dispositions are intrinsic properties of their bearers. This is one of the crucial appearances which has to be saved in an analysis" (1993: p. 3). Mark Johnston writes in an influential paper: "A disposition must have its basis in its intrinsic properties of the disposed object" (1992: p. 234). That dispositions are intrinsic appears to be a widespread view that is deeply rooted in Westerners' thinkers.

We may strengthen the above remark by seeing how Jennifer McKitrick (2003) argues for the extrinsic disposition thesis. Note first that McKitrick is among very few contemporary Western philosophers who have explicitly offered considerations in support of the extrinsic disposition claim. She proceeds by providing a few instances of dispositions, and tries to persuade the readers that each of them is an extrinsic disposition. For example, the disposition of a key to open a door, as McKitrick claims, is extrinsic. For, it could lose its disposition of 
opening a door without having any change in its intrinsic properties. A change of the lock of the door would do the trick. Since the lock of a door is extrinsic to a key, and the characterization of the disposition of opening a door has to involve the lock of the door, a key's disposition to open a door is extrinsic.

Similarly, the defensibility of a castle is also an extrinsic disposition. For, without changing any intrinsic properties of a castle, the defensibility of a castle could be altered simply by considering the kind of enemy that attempts to invade it. McKitrick has provided a few other cases, such as recognizability, visibility, vulnerability, weight, etc., and tried to show that they are extrinsic dispositions. What is particularly interesting to note is that according to the way McKitrick argues for the extrinsic disposition thesis, a majority of dispositions would count as extrinsic, including the disposition of fragility that is widely regarded as a paradigmatic example of dispositions. Nonetheless, McKitrick explicitly states her aim as simply trying to prove that there are at least a few positive cases of extrinsic dispositions. In my view, making a humble claim like this serves as an obvious indicator that the belief in the intrinsic disposition thesis is basic and deeply embedded in the Western way of thinking about the world.

Why is this so? Why do the Westerners hold a presupposed view that a disposition is intrinsic, whereas the (ancient) Chinese tends to see a disposition as extrinsic? I think that this contrast has a lot to do with a God-based versus a Godless worldview. Consider John Locke's famous claim that personal identity consists in a person's memory and consciousness across time. A person at $\mathrm{t} 1$ would be the same person at $\mathrm{t} 2$ insofar as the person at $\mathrm{t} 2$ remembers what he or she has done or thought at $\mathrm{t}$. Locke takes great interest in answering this metaphysical question not simply because it is philosophically intriguing, but also because of a deep religious concern. When the Judgment Day comes, it has to be a same person that has to be brought in front of God for what he or she has done in the past. Now imagine that a same person has been successfully identified and brought to face God, by applying Locke's criterion of memory and relevant psychological properties. Suppose, then, we were told that the deeds of a person is caused by a variety of dispositions that are by nature extrinsic. That would imply that the notion of responsibility, rewards and punishments, could not be ascribed to an individual person, for those extrinsic factors often fall outside the control of the person. This would be disastrous in the face of Christianity. In this light, we see 
how the acceptance of the intrinsic disposition thesis may have a strong religious root that remains resilient in modern Western civilizations.

\section{From Higgs' Boson to Northoff's Brain}

Discussions in the previous section may afford us a special cultural perspective to appreciate a recent breakthrough in particle physics that leads to the winning of 2013 Nobel Prize: the discovery of Higgs' boson. The novelty of this theory lies in its hypothesizing that the mass of an object results from the force of resistance while the object moves along a field (called "Higgs' field") filled by tiny particles (called "Higgs' boson"). In this hypothesis, the property of mass possessed by an object amounts to an extrinsic property of the object, for the property of mass relies on features outside the object to determine it. This idea goes against a long entrenched view that mass differs from weight, in that the determination of the latter depends on a surrounding gravitational field, whereas the former does not. The theory of Higgs' boson refutes the traditional view that mass is an intrinsic property of an object. This may partly explain why not much attention was paid to the hypothesis when it was first proposed by some physicists in the 1960's. That a property as basic as mass is extrinsic is at odds with a latent but dominant assumption that a disposition is intrinsic, which has its root in a Godbased worldview.

Shall we expect to find similar influences of the intrinsic view of dispositions coupled with a God-based worldview when we turn to the area of investigation of the human mind? The answer is positive and no less surprising, as I shall show. Northoff's pioneering studies on the mind-brain relations may serve as a focal point for showing how our conceptions of human mind are deeply mediated and influenced by our cultural-historical-religious heritages. To get our discussion going, we start by illustrating the ideas of domain and methodology pluralisms central to, and distinctive in, Northoff's non-reductive version of neurophilosophy.

In traditional philosophy, inquiring the nature of mind has been a metaphysical pursuit, aimed at uncovering the nature of human mind through conceptual and logical reasoning and analyses. As science started to gain its momentum and entered into the central stage of human intellectual enterprise, adopting an observational-experimental methodology has become necessary and even dominant in the study of mind. Thus, we have witnessed how various movements in the study of 
mind in the $20^{\text {th }}$ century in the Anglo-American philosophical communities are largely shaped by empirical disciplines in relevant fields, such as behaviorism in psychology, functionalism in computer science, and most recently, neurophilosophy in brain science. For radical philosophers such as Patricia and Paul Churchland, a reductive approach is favored. They offer a so-called bootstrapping methodology, where only neuro-concepts and empirical data are allowed as legitimate apparatuses and raw materials from which prediction and explanation of mental phenomena are deduced. As a result, consciousness and a sense of self that are characteristics of the human mind should be eliminated from our ontological view of the world. A reductive approach thus replaces a rationalistic-argumentative methodology by an observationalexperimental one, and shifts the metaphysical domain entirely to the empirical domain in the study of mind. We may thus say that this/such reductive approach adopts domain-monism and methodology-monism.

Northoff has observed that a reductive approach is inspired by, and continuous with, Quine's agenda of naturalizing philosophy. Through a series of influential writings as in "Two Dogmas of Empiricism" (1953) and Word and Object (1960), Quine has placed philosophy on a same level and status as science, a discipline deemed as a paradigm for philosophy. In this view, only things that are observable and subject to empirical tests can be ascribed with content and understanding. It is a natural extension to think that adopting a thirdpersonal and objective stance toward the brain is a legitimate and ultimately supreme way to studying the human mind. Statements that contain mental notions such as intentionality and consciousness do not preserve truth value as extensional language does, and hence are not treated as proper items to be employed in an intellectually vigorous and respectful inquiry.

Northoff disagrees with Quine, however, in holding that the firstperson phenomenology has to be taken as a legitimate starting point for a scientific research of the mind. As Northoff sees it, the empirical domain should be incorporated without making sacrifices in the metaphysical domain. In a similar vein, the observational-experimental methodology should be adopted together with the employment of conceptual-logical analyses. This position is motivated by seeing the need and importance of preserving the phenomena of our first-person experiences when conducting a neuro-scientific study of the human mind. Coming from an intellectual background of phenomenology himself, Northoff's brain research tries to incorporate its insight concerning how body and mind 
are intricately related. An important source of inspirations comes from Phenomenology of Perception (1965), where Merleau-Ponty relies on the works of German neurologists such as K. Goldstein and E. Strauss to link human consciousness to the brain's sensorimotor functions. In his idea, the mind has to be anchored in a body, thus rejects what Descartes has influentially advocated in a mind-body dualist thesis. In a neurophenomenological approach like this, the first-person experiences are not abandoned in the neuroscientific study of the mind. To implement this idea, Northoff adopts a "concept-fact iterativity" methodology, where first-person concepts are permitted in neuroscientific theoretical constructions. Based on the experimental results derived from those constructions, revision on the original hypotheses can be made for further empirical tests, thus going on in a loop. Since this way of doing things requires that the philosophical analysis of first-person concepts combine with empirical work on third-person observational data, this is a form of what Northoff calls "domain and methodological pluralisms".

This non-reductive approach of neurophilosophy enables Northoff to derive some breaking-through results, where two features of the brain are among some of the most salient. One is that the brain has a certain intrinsic structure, typically associated with the Default-ModeNetwork (DMN) and Cortico-Midline-Structure (CMS) that is causally responsible for consciousness and a sense of self. Another feature is that the brain is intrinsically linked to its body and environment, something that is inevitably in constant interaction with stimuli from outside. In this view, a brain plays a necessary role in the production of consciousness and a sense of self, but not sufficient unless its body and surrounding environment enter into the causal nexus with it. Northoff characterizes this position as a brain-based, not brain-reduced account of the mind.

We may illustrate these two ideas in some more details. The first one is stated as a hypothesis that the brain is in a constant process of activation as a result of its intrinsic features being continuously interacting with stimuli from both internal and external sources. Following the insight of Kurt Goldstein (2000), Northoff (2014b) views the brain as a system that is never truly at 'rest', but in a continual state of excitation. Some neuroscientists, such as Charles Sherrington (18571952), used to favor the view that the brain and the spinal cord are a primarily reflex system, which is at rest but only get reacted when stimulated externally. An important part of Northoff's work is to show both that intrinsic features are as critical as external stimuli in bringing 
about patterns of activation in the brain and what the structure and form of the brain's intrinsic features are like.

This hybrid-factor view of the brain in terms of its intrinsic and extrinsic properties can be corroborated by a neuroanatomical study of the brain, as Northoff claims (2014b). The brain is structured into different regions such as, for instance, the cortical and subcortical regions, which are also connected to each other by various tracts and fibers. Traditionally, the brain is divided into medial and lateral parts as well as into subcortical and cortical regions. This can be observed from outside the brain. However, this initial anatomical observation has then been questioned by Nieuwenhuys (1996, 1999), who proposed an integral cortical and subcortical system and refined the medial-lateral distinction into a threefold ring-like distinction: inner, middle, and outer, similar to the different layers of an onion, forming a radial-concentric organization. One of Northoff's central theoretical claims is that CMSs remains highly active and consumes much energy during a resting state - an intrinsic feature of the brain that makes it a perfect candidate for the location of a sense of self.

The second idea is expressed by the environment-brain unity hypothesis, which is based on the first idea and develops further from it. According to Northoff (2014b, Vol. II, Chapter 20), the concept of "environment-brain unity refers to a virtual statistically based linkage between the brain's intrinsic activity and the occurrences of stimuli from the environment across different discrete points in (physical) space and time. This concept is backed up by empirical findings, showing that the brain's resting state activity encodes into its neural activity the statistical frequency distribution of the stimuli in the environment. More specifically, the phases of the low-frequency oscillations of the brain encode the statistically-based temporal and spatial differences of the stimuli's occurrences in the environment across different discrete (physical) space and time. This implies that the statistically-based encoding of the natural and social structure of the extrinsic stimuli into the brain's intrinsic resting-state activity serves as a base for the constitution of a virtual statistically based spatiotemporal unity between brain and environment. A similar account can be applied to investigate the relation between the brain and the body, which can also form a unity, given the statistically-based encoding connection being developed and built between the resting activity of the brain and the environment's stimuli. Given the nature of brain-environment unity as such, the 
intentionality of consciousness can also find its causal basis in neuralpredisposition.

A brain study of the human mind also has an ethical dimension, which in the contemporary Western context typically has two components. One is the ethics of neuroscience. Another is the neuroscience of ethics. The former has to do with ethical issues involved in neuroscientific researches. For example, certain experimental designs may bring potential harm to subjects in physical, psychological or social aspects. Caution and suitable legal procedures have to be considered and taken for those occasions. The latter deals with the involvement of the brain in human moral behaviors. Conducting experiments to investigate, for instance, patterns of neural activations underlying decision-making in one's ethical life may help revealing whether emotions play a role in morality and how central its role is. Northoff maintains that these two components are interrelated, and can be incorporated into his nonreductive neurophilosophy.

We shall not go into the details of Northoff's rich discussions of the mind-brain relations any further, due to the limited space here. What has been sketched suffices to show the novelty of Northoff's neurophilosophical approach and its relevance to our current concern, that is, to construing consciousness and a sense of self as an extrinsic property of a person. Indeed, the brain as a neuro-basis of the human mind is only a necessary part of an integral unity that includes a body and its environment. This goes against a strong intuition widely shared in Western traditions, represented by reductive neurophilosophers, that a sense of self and consciousness are properties intrinsic to an individual person.

\section{Linking Neurophilosophy to Chinese Philosophy}

What would the human mind be conceived of in a tradition that embraces a Godless worldview? A look at the traditions of Chinese Philosophy reveals that (the) mind is regarded as an integral part of the world, rather than an isolated entity that holds existence independent of surroundings, hence it exhibits extrinsic properties of sorts. This view has been prevalent throughout the intellectual history of China, salient already in the Warring States era $\left(2^{\text {nd }}\right.$ to $4^{\text {th }}$ centuries BC), and getting particularly well articulated by thinkers in the late Song and Ming dynasties $\left(12^{\text {th }}\right.$ to $17^{\text {th }}$ centuries), a trend also shared by the intellectual legacy of Japan and Korea. Since the philosophical traditions of China are rich and complex, 
I will focus on the two aforementioned periods just to briefly remark on some of the central ideas that are relevant to our current concern.

One of the most important dogmatic features within Chinese intellectual tradition is an emphasis on Man-Heaven relationship, as some influential scholars have noted. For example, a historian of Chinese thoughts at Princeton University Ying-Shi Yu (2014) has suggested that the transition, from conceiving of the Heaven ( 天 )-something transcendentally spiritual-as belonging to the realm of divinities accessible by man only through the mediation of witches (巫) to conceiving of it as being connectable to man through personal efforts by turning inward, marks the so-called "axial breakthrough" of the civilization of ancient China shared by other ancient civilizations such as in Greece, India, Israel, etc. as observed by Karl Yaspers (1953). The idea of the Heaven is ubiquitously understood among different schools of thought in ancient China in terms of Dao (道) and Chi (氣). As Mencius expressed: “Chi is such that it matches to Just and Dao" (其為氣也, 配 義與道). Zhuangzi stated, “Chi is something that is empty, such that objects can be incorporated and nourished in it; it is through Dao that Chi consolidate” (氣也者, 虚而待物者也。唯道集虚。). Guanzi said, “Spirits are Chi in nature. Chi and Dao lead to life" (精也者, 浄之精也。 氣道乃生). In each of these conceptions, Dao is the source of life and all things in the world, as well as value, and is inseparable from Chi. What this amounts to is clearly a chi-based cosmology.

In this chi-based worldview, heaven, earth, man, and numerous things in the world are all parts of an organic integral whole. So, for example, Mencius said, "Hundreds of thousands of objects are readily embedded in me", and Zhuangzi maintained, "The Heaven and earth coexist with me, and hundreds and thousands of objects and I are one", etc. The possibility of human life is also understood on the basis of the concept of chi: "Life of human is the condensation of chi. Condensation of chi leads to life, and dispersion of chi results in death" (Chapter on Knowledge Wandered North, the Zhunagzi), or "Where there is chi, there is life; where chi is inexistent, there is death Chi is what life is based" (Chapter on Shu Yan, the Guangzi). A human being has more than just a biological life; it also enjoys a rich mental life, where a sense of self is a crucial element of it. How, then, does the mental aspect fit into this chibased worldview in ancient China?

In an inquiry of the philosophical writings of Zhuangzi, I (Cheng, 2014b) attempted to show that the phenomena of mental life on the one 
hand and the seeming existence of a self on the other hand in a person have been acutely observed and distinguished. The mental life consists of numerous mental states that come and go while being awake and even asleep. A self is highlighted and characterized as a "True Master" that appears to hide behind and governs the occurrences and transitions of mental states. Zhuangzi does not address the issue concerning the nature of mental states in the way as contemporary Western philosophers do, with regard to investigating whether mental states are ontologically distinct from physical states in a dualistic manner. He seems to place the inner mental life and outer physical occurrences (exemplified by three pipes of sound: sound of man, sound of earth, and sound of heaven) as equally on a par in the natural order that is chi-based. What gets in the way of assimilating both physical and mental states into the same natural order is the seeming existence of a self-something whose existence is felt with certainty without a trace of empirical proof. In my reading, Zhuangzi has presented an ingenious argument in the dream of the butterfly story, showing that a persistently existing self-a True Master - is an illusion. Thus, despite the fact that an individual person has a body enjoying a rich mental life that is distinguishable from other objects, they can all enter into a natural order of transformation that is chi-based. This view places a person at a very different locus from that in a Western tradition exemplified by Socrates' identification of self as soul and Descartes' construal of self as a thinking substance. The latter places the ontological priority of a logical/agency-based world over a natural/chi-based world, whereas the former embeds a logical/agencybased world within a larger and ontologically more basic natural world.

The chi-based worldview has been further developed in the subsequent intellectual history of China, where the relation between mind, body and the environment was more explicitly addressed. One of the central theses proposed in the era of the $14^{\text {th }}-16^{\text {th }}$ centuries is the idea that shin (性, quality/nature) is greater than $\operatorname{xin}$ (心, heart/mind. The former (shin) notion is usually understood in terms of the notion of chi, signifying something that permeates a greater environment encompassing an individual person's body and that gives rise to the natural order of things in the world. The later (xin) notion is taken to refer to something that can engage in thinking, sensing, and feeling. The idea in question is that the chi-based nature (shin) dominates and regulates the human mind (xin). For example, a Confucian scholar Ting-Han Wu (吴廷翰, 14911559) writes as follows: 
Shin...is where the human mind is born, yet it is not easy to be detected, and no names or items are attached to it. It consists of something that is holistically undifferentiated. The human mind (xin) is as it is, because of its acts of cognizing and perceiving, and it's being capable of doing all these is due to shin. Shin is invisible, and becomes perceptible only when it manifests in facts. Shin develops into facts, and then put into use. If the will makes a decision, and the intellect thinks a thought, then they are the products of the exercising of xin, which are in turn derived from nothing but $\operatorname{shin}^{1}$.

Wu acknowledges the fact that the human mind (xin) has some special status because of its mental characteristics/abilities, such as performing acts of decision-making, thinking, and perceiving. Nevertheless, these mental acts are regulated and made possible by shshinin, a holistically undifferentiated whole of a chi-based surrounding, rather than the other way around. In this view, the human mind is essentially embedded in the natural environment. There is a continuous and unified relationship between the two.

Though a more thorough survey and illustration is needed to make clearer the complex ideas of shin and xin, the discussion above suffices to show that one salient way in which Chinese thinkers conceive of the human mind is that its constitutive conditions involve external factors from the body and environment. This is a worldview that is fully congenial to make sense of Northoff's neurophilosophical study of the mind-brain problem. Both agree on not to reduce mind to brain (or bodyenvironment) or the other way around, and seek to situate the mind/brain in a holistic circumstance in the understanding of its surroundings. In other words, some basic presuppositions in the mainstream Western conceptual framework, such as reductionist methodology, an intrinsic view of (dispositional) property, etc., to which Northoff's non-reductive neurophilosophical approach presents itself as an alternative, are entirely compatible with the Chinese ways of understanding the mind-world relationship.

There is perhaps one aspect in which Northoff's non-reductive approach differs from the Chinese view. In the ethical dimension, Chinese intellectuals emphasize the cultivation of virtuous characters and practice of moral actions on a chi-based ground. A basic idea, as 
proposed by Ting-Han $\mathrm{Wu}$, is that xin (the heart-mind) has to engage in the exercises of being alert in solitude (戒懼慎獨) and put it into practice in daily life activities, such that shin (quality-nature) can be fully realized and manifested (盡性). By doing so, the good can be achieved. Two features in this view are worth noting. One is that the metaphysical and the ethical in the Chinese way of thinking are intimately connected. A chi-based worldview invites a natural extension from a metaphysical picture of the world to an ethical dimension of how to act and live in a social-political world. Given that a person and the environment are ontologically continuous permeated by $c h i$, certain practices can be acquired and adopted to adjust the configuration of chi in oneself and the surroundings to achieve a level of balance that approximates the ideal of the good. In a reverse order, it may not be too unreasonable to say that, the ethics of actions and practices seems to be placed by the Chinese intellectuals at the center, and given top priority, of considerations, and the metaphysical pursuit was conducted out of the motivation to find ground for the ethical need. Another implication is that there is no sharp distinction between fact and norm, as typically stressed in the Western intellectual traditions. David Hume famously points out that there exists a dichotomy between the factual and the normative, and claims that it's an error to conflate the two. A similar line of reasoning is adopted by G.E. Moore, who calls it a "naturalistic fallacy" to reduce the moral property of the good to any other items. Such a dichotomy is obviously absent in the Chinese intellectual traditions. What guides a morally good action in the Chinese conception of morality is not rule-governed, which is typical in the Western traditions such as Kantian ethics and Utilitarianism. Rather, it is achieved through practices in the cultivation of $c h i$ in certain manners. A naturalistically understood notion of $c h i$ has value implicitly embodied in it, which gets manifested through actions sprout from the exercising of suitably cultivated chi. No strict lines are drawn between value and nature or norm and fact in the Chinese worldview.

This ethical view is very different from Northoff's non-reductive neurophilosophy when he proposes domain pluralism which incorporates the metaphysical, epistemological, ethical, and the empirical into a synthesized study of the human mind. The ethical aspect that is touched upon in his view is either the neuroscientific study of moral behavior or the ethical issues concerning the design and conducting of neuroscientific experiments. Given the ontological view held by Northoff in which the mind-brain is regarded as being connected to body and environment, we 
may expect him to take a holistic perspective to look at human moral behavior that involves the interaction between and constantly mutual adjustment of the mind/brain and the physical, social and cultural environment. That might lead to an ethical view very different from a rule-based view of morality exemplified by Kantian ethics and Utilitarianism. In any case, there is obviously more to be developed in Northoff's neurophilosophy concerning ethics, and Chinese philosophy in this regard would be a resourceful point of reference worthy of consideration.

\section{Conclusion}

The advances in the neuroscience are exciting, mainly because it studies the brain, which is key to our understanding of the human mind, especially regarding self and consciousness. Discussions in the previous sections show that certain implicit presuppositions held in different cultural and intellectual traditions may deeply influence neuroscience researches. To spell out those presuppositions helps reveal ways in which a non-reductive approach such as one taken by Northoff may encounter resistance from the mainstream neuroscience and ways in which this approach may constitute a paradigm shift. What I hope I have demonstrated in this initiative is that the openness of neuroscience to Asian intellectual traditions can enrich its theoretical resources, and Asian intellectual traditions can also be revived and gain new momentum through this kind of conceptual exchanges with neuroscience.

\section{Endnotes}

${ }^{1}$ Collections of Ting-Han Wu: Chi Zai Man Lu (吳廷翰集 : 吉齋漫錄). The original text goes as follows: 「性...人心之所以生也。然在其中 未易窥測，亦無名目，渾淪而已...人之所以為人者，皆心之所以知 覺運動之，而心之所以能者，則性為之，但性不可見，因情而見耳。 性發為情, 而其能為才, 若志意思慮, 是又緣心而起, 然亦莫非性 之所為也。」

\section{References}


Cartwright, N. (1983). How the Laws of Physics Lie. Oxford: Oxford University Press.

Cartwright, N. (1989). Nature's Capacities and Their Measurement. Oxford: Oxford University Press.

Cartwright, N. (1999). The Dappled World: A Study of the Boundaries of Science. Cambridge: Cambridge University Press.

Cheng, K. Y. (2014a). Laws and Capacities: Rethinking a Contrast between Eastern and Western Worldviews. Kesturi.

Cheng, K. Y. (2014b). Self and the Dream of the Butterfly in the Zhuangzi. Philosophy East and West.

Churchland, P. (2007) Neurophilosophy at Work. Cambridge, MA: Cambridge University Press.

Churchland, P. (2002). Studies in Neurophilosophy. Cambridge, MA: MIT Press.

Goldstein, K. (2000). The Organism. Zone Books.

Heil, J. (2003). From an Ontological Point of View. Oxford: Clarendon Press.

Heil, J. (2015). Real Modalities. In J. Jacobs (Ed.), Causal Powers. Oxford: Oxford University Press.

Johnston, M. (1992). How to Speak of the Colors. Philosophical Studies, 68, 221-63.

Jullien, F. (1995). The Propensity of Things: Toward a History of Efficacy in China. Cambridge, MA: MIT Press.

Jullien, F. (2004). A Treatise on Efficacy: between Western and Eastern Thinking. Honolulu: University of Hawaii Press.

McKitrick, J. (2003). A Case for Extrinsic Dispositions. Australasian Journal of Philosophy, 81, 155-174.

Merleau-Ponty, M. (1965). Trans: Colin Smith. Phenomenology of Perception. London: Routledge \& Kegan Paul.

Molnar, G. (1999). Are Dispositions Reducible. Philosophical Quarterly, 49, 1-17.

Nieuwenhuys, R. (1996). The Greater limbic system, the emotional motor system and the Brain. Emotional Motor System, 107, 551580 .

Nieuwenhuys, R. (1999). The Morphological Pattern of the Vertebrate Brain. European Journal of Morphology, 37(2-3), 81-4.

Northoff, G. (2014a). Minding the Brain. Palgrave.

Northoff, G. (2014b). Unlocking the Brain, Vols. 1 \& 2. Oxford: Oxford University Press. 
Quine, W. V. (1953). From a Logical Point of View. Cambridge, MA: Harvard University.

Quine, W. V. (1960). Word and Object. Cambridge, MA: MIT Press.

Wu, T. H.: Collections of Ting-Han Wu, Chi Zai Man Lu (吳廷翰集：吉 齋漫錄)

Yu, Y. S. (2014). An Essay on the Relationship between Heaven and Man, Lien-Ching Publisher. 論天人之際, 聯經出版社 